Document downloaded from:

http://hdl.handle.net/10251/72912

This paper must be cited as:

Desantes J.M.; Torregrosa, AJ.; Broatch, A.; Olmeda González, PC. (2011). Experiments on the influence of intake conditions on local instantaneous heat flux in reciprocating internal combustion engines. Energy. 36(1):60-69. doi:10.1016/j.energy.2010.11.011.

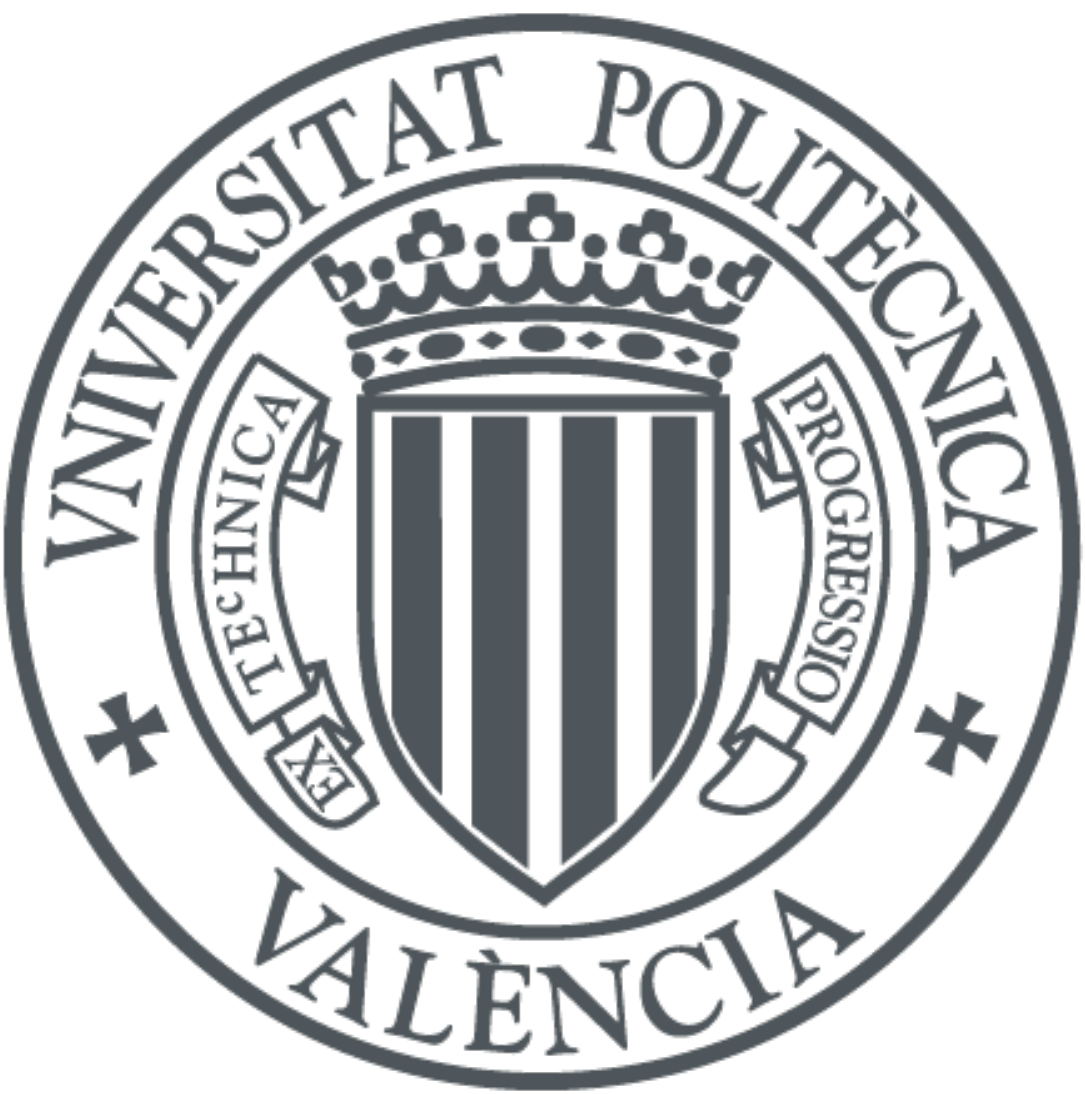

The final publication is available at

http://dx.doi.org/10.1016/j.energy.2010.11.011

Copyright Elsevier

Additional Information 


\title{
Experiments on the influence of intake conditions on local instantaneous heat flux in reciprocating internal combustion engines
}

\author{
J.M. Desantes, A.J. Torregrosa, A. Broatch, P. Olmeda* \\ CMT-Motores Térmicos, Universidad Politécnica de Valencia, Aptdo. 22012, E-46071 \\ Valencia, Spain.
}

\begin{abstract}
The present study tries to be a contribution for the development of more precise theoretical models for predicting the dissipation of heat through the combustion chamber walls of reciprocating IC engines. A fast response thermocouple was embedded in the combustion chamber of a single cylinder engine to measure instantaneous wall temperatures. The heat flux was obtained by solving the one-dimensional transient energy equation with transient boundary conditions using the Fast Fourier Transform. The engine was tested under different operating conditions to evaluate the sensitivity of the measurement procedure to variations of three relevant combustion parameters: injection pressure, air temperature and oxygen concentration at the intake. The local heat flux obtained was compared with other relevant parameters that characterize the thermal behaviour of engines, showing, in most of the cases, correlation among them. The results showed that the instantaneous heat flux through the walls and hence the local wall temperatures are
\end{abstract}

\footnotetext{
${ }^{*}$ Corresponding author. Tel.: +34 96 3877650, fax: +34 963877659 .

Email address: pabolgon@mot.upv.es (P. Olmeda)
} 
strongly affected by the ignition delay and the start of combustion. Key words: Internal combustion engines, instantaneous heat flux, local heat flux, instantaneous wall temperature, fast response thermocouple 


\section{Nomenclature}

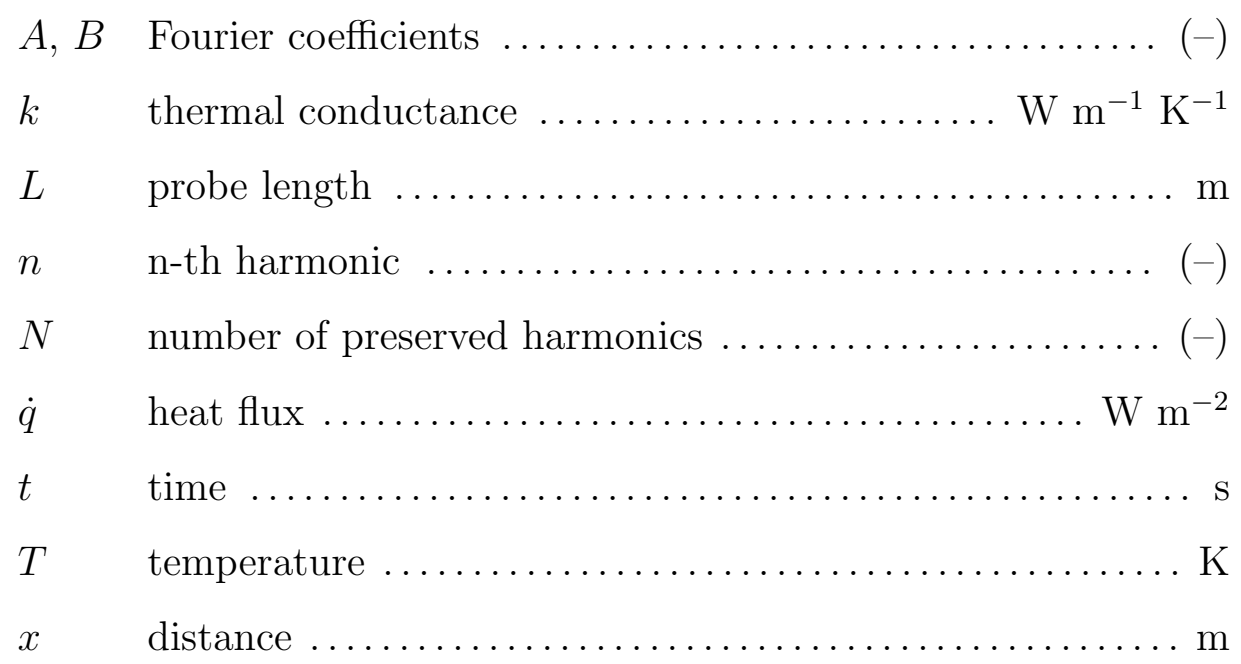

Greek symbols:

$\alpha \quad$ thermal diffusivity $\ldots \ldots \ldots \ldots \ldots \ldots \ldots \ldots \ldots \ldots \ldots \ldots \ldots \ldots \ldots$

$\omega \quad$ angular velocity $\ldots \ldots \ldots \ldots \ldots \ldots \ldots \ldots \ldots \ldots \ldots \ldots \ldots \ldots$

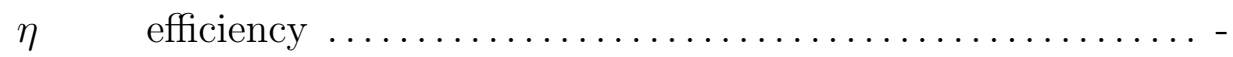




$\begin{array}{ll}\text { Subscripts: } \\ m & \text { mean } \\ n & \text { n-th harmonic } \\ 0 & \text { initial } \\ i & \text { indicated }\end{array}$

Abbreviations:

CAD crank angle degree

EGR exhaust gas recirculation

f.s. full scale

IC internal combustion

imep indicated mean effective pressure

IVC intake valve closing

LHR low heat rejection

RoHR rate of heat release

SOC start of combustion

TDC top dead centre

\section{1. Introduction}

2 Heat transfer from in-cylinder gas to the combustion chamber walls in 3 IC engines is one of the most influencing parameters on engine performance, 4 efficiency (fuel consumption) and exhaust pollutant emissions. In addition, 5 it is one of the worst known processes in IC engines due to its complex6 ity: convection and radiation mechanisms, turbulent reactive fluid dynamics, 
wall deposits, three-dimensional and transient phenomena, and cycle-to-cycle fluctuations. This complexity has induced some authors to write that "the problem is a modeller's nightmare and an experimenter's agony, but is far too important to ignore" [1]. In the last years, mostly due to the need of engine improvement, big efforts have been devoted to developing suitable theoretical and experimental tools for improving engine designs [2].

Furthermore, the knowledge of heat transfer phenomena in IC engines plays an important role in successfully simulating thermodynamic cycles and consequently the thermal load of the combustion chamber components can be estimated more precisely $[3,4]$. This fact is crucial also for the mechanical design of these components, which car manufacturers frequently face at early stages of engine development. Moreover, there are no doubts that IC engines have had to overcome many difficulties along the years to face high-efficiency demands but complying with restrictive legislations regarding pollutant emissions. Since emission formation is very sensitive to wall heat transfer, several studies have been focussed on validating new technologies $[5,6]$ and defining suitable strategies for the reduction of the engine warmup time [7]. With this purpose, Low Heat Rejection (LHR) engines covering the combustion chamber walls with ceramic film [8] have been evaluated and strategies for controlling the coolant flow through the engine $[9,10]$ or for heating the intake air $[7,11]$ have been explored.

In these studies, the importance of a precise characterization of the heat transfer phenomena in the combustion chamber was remarked. Regarding this subject, research activities are often focused whether on applying different thermal analyses based on simple resistive models $[12,13,14]$ or on 
performing complex and highly time consuming calculations with three dimensional fluid dynamics models $[15,16]$. In both cases, the common challenge lies on the determination of a suitable film coefficient for the assessment of the convective heat transfer from in-cylinder gas to combustion chamber walls. This coefficient is frequently determined by a general correlation as those proposed by Woschni [17] and Annand [18], whose results were based on a global heat balance of the engine and presented considerable discrepancies between them. Since the suitability of these correlations for determining the heat flux through different elements of the combustion chamber is at least debatable, more precise and detailed coefficients are required to obtain a more realistic thermal characterization of engines [19]. With this purpose, combustion chamber splitting has been used for calculating spatial film coefficients in the cylinder by means of the Colburn analogy [8].

In order to measure the heat flux through the engine components (cylinder, cylinder head and piston) different sensors can be used, those most used being the fast response thermocouples [20,21]. Due to the reciprocating movement of the piston, its wall temperature signal is acquired by means of telemetric systems [22, 23], which can be mechanical, magnetic or optical.

In this work fast response thermocouples were used to determine the instantaneous heat flux through combustion chamber walls, by using a specific test bench designed for basic combustion studies in Diesel engines. The main objectives of the work were focused first on evaluating the suitability of this technology and verifying the sensitivity of the sensors for measuring instantaneous heat flux. Then, the effect of different parameters, such as intake air temperature, injection pressure, and oxygen concentration at the intake, on 
the heat flux through combustion chamber walls was analyzed.

The paper is organized into four sections. First, a brief discussion of the test bench, including the most relevant measuring system used, is presented. Then, the main assumptions and the mathematical method used to determine the instantaneous heat flux is thoroughly explained. In section 4 , the results obtained are discussed. Finally, the main conclusions extracted from the study are summarized.

\section{Test equipment}

The experimental set-up used in this study has been fully described in a previous work by Bermúdez et al. [24]. In this section a brief description of the principal characteristics of the test rig will be only presented. This experimental apparatus is a physical model that reproduces the thermodynamic conditions of the air (pressure, temperature and density) which are expected inside the cylinder of current direct injection Diesel engines at the start of injection, so that injection-combustion processes can be studied in almost real conditions. The main element of the layout is a single cylinder port-scavenging two-stroke engine with three-litre displacement and low rotational speed $(\sim 500 \mathrm{rpm})$. The geometrical characteristics of this engine are presented in Table 1. Since the fuel mass injected was not enough so as to obtain a positive net power output, the engine was motored to maintain constant its operating conditions.

Fig. 1 shows a scheme of the experimental set-up and the monitoring equipment used in this study. Intake air was supplied to the engine by an oil-free screw compressor with 4.5 bar of maximum outlet pressure, so that 
the intake pressure could be controlled up to almost that level. After the compression the air was cooled and dried (dew point temperature $\sim 3{ }^{\circ} \mathrm{C}$ ) and its temperature controlled. The temperature of the air in the settling chamber was regulated by means of a conditioning system. The capacity of this system was $4.5 \mathrm{~kW}$ heating and $6 \mathrm{~kW}$ cooling, with which a control range of the intake air from ambient temperature up to $420 \mathrm{~K}$ was available. The oxygen concentration of the intake air was reduced by introducing exhaust gases from a spark ignition (SI) engine used as a gas generator. As shown in Fig. 1, exhaust gases from the SI engine were conveyed to the settling chamber and its mass flow rate was regulated with a linear-response valve as a function of the oxygen concentration set value. Air conditions in the intake settling chamber were monitored for precisely determining the thermodynamic parameters of the charge in the cylinder at any operating conditions.

Fig. 2 shows a cross sectional view of the cylinder head of the 2-stroke engine, which contains a cylindrical combustion chamber (45 mm diameter, $53 \mathrm{~mm}$ height). The injector is located in the upper side of the chamber, and four optical accesses are available in its lateral sides. One of the lateral accesses was used for assembling the pressure transducer, as can be seen at the left hand side of Fig. 2, while a second optical access was replaced with the heat flux probe (right hand side).

The fuel injection was electronically controlled by a Bosch fuel injection system with common rail, allowing for injection pressures from 300 bar to 1300 bar. The injector was equipped with a mini-sac single-hole axial nozzle. The injection control system was purpose-developed in order to permit the 
variation of any parameter of the injection strategy, that is: timing, energizing time, injection pressure and number of injections. To minimize window fouling, the engine was run under a skip-fire mode (i.e. fuel injection is triggered only after a predefined number of cycles) and short injection durations were used.

To avoid problems with engine lubrication and high vibration levels due to low rotational speeds, in all the tests the engine was operated at $500 \mathrm{rpm}$. Higher rotational speeds were limited by the speed of the electrical motor. In addition, the maximum gas pressure in the combustion chamber did not exceed 80 bar since it was limited by the resistance of the quartz windows used in the optical accesses.

Walls temperature of the engine was controlled by an external heatingcooling system during the tests. In this study, the coolant temperature at the inlet of the engine was kept constant to $70{ }^{\circ} \mathrm{C}$ for all conditions tested.

The measuring systems used can be divided into two main categories. In the first group the instrumentation for controlling the experiment and for characterizing the engine operation is included, while the specific equipment for measuring the instantaneous heat transfer from the gas in the cylinder can be considered in the second category.

Regarding the first group, the test bench and the engine were equipped with usual instrumentation for the quantification of parameters that characterize the operation of IC engines. With this purpose, transducers for test control and for engine operation diagnosis were used. For the characterization of non-steady processes, dynamic pressure sensors were used in the cylinder and in the intake and exhaust systems. In-cylinder pressure evolution was 
measured by means of a Kistler $6067 \mathrm{C} 1$ piezoelectric sensor. All these variables were synchronized recorded. The synchronization signal was generated by an optical encoder coupled with the crankshaft of the engine. Apart from the evolution of non-steady variables, mean pressure and temperature in different systems of the engine were measured with adequate instrumentation as it is shown in Fig. 1.

Concerning to the second group, specific equipment was employed for measuring the instantaneous heat flow transferred from the gas in the cylinder to the walls. The response time of this device is short enough as to track the abrupt heat flow changes that were expected during combustion. This performance was achieved by means of coaxial surface thermocouples, in which a constantan wire is swaged over a second chromel wire with an electrical insulation in between. Fig. 2 shows a scheme of this thermocouple. The electrical bridge between the two materials is obtained by grinding the head with dry sand paper. The customized probe was manufactured by Müeller Engineering and its response time is about 3 microseconds. The sensing area was flush mounted to the combustion chamber surface by means of the heat flux probe shown in Fig. 2, which was specifically designed for this study. In this scheme a second thermocouple (surface thermocouple) or back-side junction, located $7 \mathrm{~mm}$ below the surface is also represented. This sensor was used for measuring the steady-state heat flux. The voltage signal supplied by the thermocouple was amplified and recorded in a fast response acquisition system. The acquired signal was finally processed in a computer to determine the instantaneous temperature. This temperature was obtained by calculating previously the output voltage of the thermocouple (before 
amplifying) applying appropriate transfer functions. Then, the temperature was calculated using the International Thermocouple Reference Tables. The instantaneous data (in-cylinder pressure, intake and exhaust pressure, wall temperatures, etc.) were recorded with a Yokogawa acquisition system with a 0.1 CAD of resolution.

\section{Instantaneous heat flux calculation}

\subsection{Theoretical background}

With the temperatures measured at the inlet and outlet walls of the heat flux probe of Fig. 2, the instantaneous heat flow transferred from the gases in the cylinder is calculated with the following assumptions [25]:

- The wall is a semi-infinite solid.

- Heat transfer is unidirectional and normal to the wall.

- Initially the whole device, i.e. internal and external surfaces, is at a uniform temperature.

- The temperature at the internal wall is the measured temperature and it has a periodic evolution, so that it can be expressed as a Fourier series.

With these assumptions the well known one-dimensional unsteady heat conduction equation can be applied. That is

$$
\frac{\partial^{2} T(x, t)}{\partial x^{2}}=\frac{1}{\alpha} \frac{\partial T(x, t)}{\partial t}
$$

where $T(x, t)$ is the instantaneous temperature at a distance $x$ from the internal surface (in contact with the gas in the cylinder) and $\alpha$ the thermal 
diffusivity of the material. In addition, according to the assumptions above, the boundary conditions of Eq. (1) are the following:

$$
\begin{aligned}
& T(L, t)=T_{0} \\
& T(x, 0)=T_{0} \\
& T(0, t)=T_{m}+\sum_{n=1}^{N} A_{n} \cos (n \omega t)+B_{n} \sin (n \omega t)
\end{aligned}
$$

In these expressions, $T_{0}$ and $T_{m}$ are the initial and the mean surface temperature, respectively, $\omega$ is the angular velocity, $A_{n}$ and $B_{n}$ are the Fourier coefficients and $n$ is the harmonic number.

Applying these boundary conditions, the solution of Eq. (1) is

$$
\begin{aligned}
& T(x, t)=T_{m}-\left(T_{m}-T_{0}\right) \frac{x}{L}+ \\
& +\sum_{n=1}^{N} \mathrm{e}^{\left(-x \sqrt{\frac{n \omega}{2 \alpha}}\right)}\left[A_{n} \cos \left(n \omega t-x \sqrt{\frac{n \omega}{2 \alpha}}\right)+B_{n} \sin \left(n \omega t-x \sqrt{\frac{n \omega}{2 \alpha}}\right)\right]
\end{aligned}
$$

and according to the Fourier law the heat flux $(\dot{q})$ through the probe is

$$
\dot{q}=-\left.k \frac{\partial T}{\partial x}\right|_{x=0}
$$

Finally, replacing Eq. (3) in Eq. (4) one gets

$$
\dot{q}=k \frac{T_{m}-T_{0}}{L}+k \sum_{n=1}^{N} \sqrt{\frac{n \omega}{2 \alpha}}\left[\left(A_{n}+B_{n}\right) \cos (n \omega t)+\left(B_{n}-A_{n}\right) \sin (n \omega t)\right]
$$

According to this equation, the heat flux through the chamber walls can be estimated from the measured instantaneous fire wall and back side temperatures. Coefficients $A_{n}$ and $B_{n}$ are determined by a Fourier analysis of the instantaneous fire wall temperature. The number of preserved harmonics $N$ was chosen so as to conserve an adequate trade-off between signal biasing and high frequency noise suppression in the instantaneous fire wall temperature. 
With this purpose, the temperature signal at motoring and firing conditions was first analyzed.

Fig. 3 shows the rough averaged (247 cycles for motoring and 13 cycles for firing) and low-pass filtered instantaneous fire wall temperatures measured during motoring tests and firing tests. The adequate signal-to-noise ratio of these temperature evolutions was obtained by preserving 25 harmonics i.e. $208 \mathrm{~Hz}$. Then the heat flux through the walls was calculated considering $N=25$ in Eq. (5). These results are consistent with the signal analysis performed by Chang et al. [26] for reducing the computational effort of instantaneous heat flux calculation.

\subsection{Error analysis}

In order to minimize as possible errors in the experiments, all sensors were calibrated following rigorously the calibration procedures recommended by the sensor manufacturers. Instantaneous pressure sensors were quasisteadily calibrated by means of a dead-weight tester with NPL and NIST traceability. Table 2 summarizes the accuracy of the instrumentation used in this work determined by the calibration. The propagation of the random errors from independent variables -which are measured with the calibrated sensors- toward functions as instantaneous heat flux and temperature swing was evaluated using the first order approach as

$$
\sigma_{f\left(x_{1}, x_{2}, \ldots, x_{n}\right)}=\sqrt{\sum_{1}^{n}\left(\left.\frac{\delta f}{\delta x_{i}}\right|_{\bar{x}_{i}} \sigma_{x_{i}}\right)^{2}}
$$

where $\sigma$ is the standard deviation and $\bar{x}_{i}$ indicates the mean value of the $i$-th independent variable. 
By means of this error analysis, the accuracy of the instantaneous heat flux and temperature swing was estimated to be within $1 \%$.

\section{Results and discussion}

The measurements were performed on skip-fire mode in which fuel was injected once every twenty thermodynamic cycles, so that 19 motoring cycles per each firing cycle were considered. The total number of firing cycles was decided considering the most adequate trade-off between sample acquisition capacity and the minimum number of cycles preserving low dispersion. After testing different combinations, a good compromise between these two factors was achieved with thirteen firing cycles. This fact led to record 260 thermodynamic cycles for each test.

With the aim to evaluate the effect of different combustion parameters on the instantaneous local heat flux, a total of 24 different experiments were performed. In these experiments, variations of the injection pressure, the EGR rate (by controlling the oxygen concentration at the intake) and the intake air temperature were considered. The effect of the injection pressure was evaluated through four levels of variation: 500, 1000, 1500 and 1800 bar, while three levels were considered for the oxygen concentration at the intake: $15 \%, 18 \%$ and $21 \%$ (i.e. without EGR). For evaluating the sensitivity of the heat flux to intake air temperature two levels were used: $50{ }^{\circ} \mathrm{C}$ and 120 ${ }^{\circ} \mathrm{C}$. The heat flux through in-cylinder walls of internal combustion engines is produced both by convection and radiation heat transfer from the gas. The radiative contribution due to soot burning might represent about one fifth of the in-cylinder heat transfer [27] . With new generation injection 
systems, this fraction could be even lower. In order to estimate the radiation contribution to the heat transfer in our experiments, the correlation proposed by Annand [28] was used. The results showed that the radiation mechanisms is responsible for 5-8 percent of the total heat flux.

\subsection{Effect of the injection pressure}

Fig. 4a presents the comparison between the temporal evolutions of the instantaneous fire wall temperature measured in motoring and firing conditions with the four injection pressure level evaluated. These tests were performed without EGR, controlling the intake air temperature to $120{ }^{\circ} \mathrm{C}$ and keeping constant the injection time. The dispersion observed in the temperature measured in motoring tests (dashed line) can be attributed to the influence of the wall temperature reached after the firing cycle, since the engine was operated in skip-fire mode during the tests.

In order to avoid signal dispersion provoked by different initial conditions at the beginning of the measurements the temperature swing -calculated by subtracting the minimum temperature to the actual value- was determined for each engine operating condition. In this way, the reference level is the same for all measured temperatures independently of the running conditions, so that the effects of the combustion parameters can be more precisely evaluated. Fig. $4 \mathrm{~b}$ shows the temperature swing for the same conditions presented in Fig. 4a. In this figure, the temperature scatter for motoring operation is now indistinguishable and it is clear that, in firing operation, the wall temperature in the combustion chamber increases as the injection pressure increases. This effect obeys to the better fuel atomization and hence to the higher combustion efficiency achieved when higher injection pressure is used, 
and also to the fact that, if the energizing time is fixed, more fuel mass is injected and therefore, more heat is released in the cylinder during combustion.

Figs. 4c-d show, respectively the instantaneous heat flux and the incylinder pressure evolutions measured for the same operating conditions. In both cases, the results are consistent with the previous comments. The heat flux and in-cylinder pressure peaks increase almost in proportion to the injection pressure increase. In concordance with other published work [19], these figures also show that heat flux peaks are produced earlier than incylinder pressure peaks, and that these are closer to the TDC the higher is the injection pressure. This observation can be supported by the fact that a longer combustion is expected since more fuel mass is injected with higher injection pressures and same injection duration.

Finally, the rate of heat release and the heat flux evolution calculated with the correlation proposed by Woschni [17] to estimate the convective heat transfer coefficient are represented respectively in Figs. 4e-f. Both parameters were calculated by means of an in-house combustion diagnosis software [29]. These results show that, despite the calculated instantaneous heat flux overestimates the measurements, the temporal evolution of both parameters is similar to those discussed previously.

\subsection{Effect of intake air temperature}

In order to evaluate the sensitivity of the fire wall temperature and the heat flux through the walls to variations of intake air temperature, tests without EGR and with 1800 bar injection pressure were performed. Figs. 5a-f show the results obtained at the two intake air temperature levels considered. 
As expected, these results show that the six parameters analyzed are sensitive to intake air temperature variations, even at motoring tests. Fig. 5a shows that the fire wall temperature increases uniformly by almost $20{ }^{\circ} \mathrm{C}$ when the intake air is warmed around $70{ }^{\circ} \mathrm{C}$. In motoring conditions, temperature swings present a scatter of almost $1{ }^{\circ} \mathrm{C}$ along the cycle, while in firing cycles this difference is similar during the compression stroke and increases during and after combustion.

Fig. 5d shows that, in motoring operation, in-cylinder pressure is reduced when the intake air temperature is increased. In this case, a warmer air mass is also expected at intake valve closing (IVC) and consequently the heat transfer toward the walls is increased. As shown in Fig. 5c, this situation is experimentally evidenced by the higher heat flux measured when the intake temperature was $120{ }^{\circ} \mathrm{C}$. This high thermal energy dissipation causes an important reduction of the charge temperature, so that the pressure in the cylinder is decreased.

The big temperature swing difference observed during combustion process, should be related with the strong influence of the temperature of the intake air on the fuel ignition delay [11]. Low intake temperatures provoke lower charge temperatures in the cylinder and hence the ignition delay is longer. This fact directly affects to the start of combustion (SOC) and therefore, to the peak temperature of the gas in the cylinder. Since the injection settings, which were the same for these tests, were chosen to provoke fuel ignition closer to the TDC, increasing the intake temperature an earlier SOC is produced (as shows Fig. 5e), so that a higher in-cylinder temperature is expected and hence, a higher wall temperature is measured. 
Additionally, Fig. 5d also shows that the in-cylinder pressure traces with the two intake air temperatures collapse when engine operates in firing conditions. This should be due to a compensation of the two effects mentioned before. Since the ignition delay is shorter, the warmer is the charge in the cylinder, the lower is the heat released in pre-mixed combustion and hence a larger quantity of fuel is burned in a slow diffusive combustion (Fig. 5e). In these conditions, as is represented in Fig. 5f, higher heat transfer toward the walls is promoted due to both the higher temperature of the charge and the longer time available for heat exchange.

\subsection{Effect of the oxygen concentration at the intake}

The effect of the oxygen concentration at the intake on heat flux and wall temperature was evaluated through tests in which the intake air temperature and the rail pressure were kept constant to $120{ }^{\circ} \mathrm{C}$ and 1800 bar, respectively. The rest of the injection settings were also maintained constant. In Figs. 6a-f the results obtained with the three concentration levels tested are presented. In the six parameters, apparent effects of the oxygen concentration are observed for firing cycles. Fig. 6a shows that the wall temperature is highly sensitive to oxygen concentration even at motoring operation, being this temperature lower the lower is the oxygen concentration at the intake (higher EGR rate).

Results in motoring conditions show that the instantaneous temperature swing is similar independently of the oxygen concentration of the intake air (Fig. 6b). However, the local heat flux and in-cylinder pressure evolutions presented in Figs. 6c and 6d evidence that local heat transfer is sensitive to the composition of the charge in the cylinder and thus in-cylinder pressure 
is also affected. These results are consistent with those obtained by Hountalas et al. [30]. This observation can be thermodynamically justified by the influence of the composition of a gas on its politropic coefficient [31]. This coefficient is reduced in proportion to the reduction of the oxygen concentration of the charge and, therefore the compression and expansion strokes are less adiabatic. Since the specific heat capacity of the mixture is higher than that for the air, lower gas temperatures are reached in the cylinder [32].

Temperature swing, in-cylinder pressure, measured and calculated global heat flux and RoHR in firing conditions show that the oxygen concentration at the intake affects also to the shape of the evolution of these parameters. These evolutions are consequence of the high sensitivity of the ignition delay to the oxygen concentration of the charge in the cylinder. For a given local equivalence ratio, combustion is delayed as the oxygen concentration of the charge is reduced. In addition, Fig. 6e shows that premixed combustion is reduced in proportion to oxygen concentration. As was discussed in the previous analyses, the start of combustion strongly affects to the heat flux from the gas and hence to the local wall temperature.

\subsection{Qualitative analysis}

Important effects on in-cylinder pressure and local heat flux have been observed when the three parameters relevant for combustion were varied. These effects were caused either by the variation of the ignition delay or by the quantity of fuel injected. As commented before, these combustion parameters were modified in this study through the variation of the injection pressure, the oxygen concentration and the temperature of the intake air. Previous results showed that these factors affect directly to wall temperatures, heat 
flux and in-cylinder pressure peaks.

In order to determine general trends of the influence of the combustion parameters on the heat flux and in-cylinder pressure peaks, a qualitative analysis was performed. With this purpose, the measured data conveniently grouped were subject to a regression analysis in order to obtain the contour plots shown in Figs. 7 and 8.

Fig. 7 shows the sensitivity of the in-cylinder pressure peak to the operating variables referred to above. As expected, these results show that, independently of the intake air temperature, the in-cylinder pressure peak increases in proportion with both the injection pressure and the oxygen concentration. This behaviour is consequent with both the larger fuel mass injected associated with fuel pressure increase -since the same injection duration was used- and the smaller ignition delay associated with an $\mathrm{O}_{2}$ concentration increase. In addition, the plots in Fig. 7 also indicate that the sensitivity of the peak pressure to injection pressure increases as the intake air temperature is increased. Contrary to this, the sensitivity to the oxygen concentration decreases as such temperature increases.

The sensitivity of the local heat flux peak to injection pressure and intake air oxygen concentration and temperature is represented in Fig. 8. As expected, these results show that higher intake air temperatures induce higher heat flux peak levels. Fig. 8a shows that the sensitivity of the heat flux peak to injection pressure and oxygen concentration at $50{ }^{\circ} \mathrm{C}$ is qualitatively different from that observed for the in-cylinder pressure in Fig. 7a. However, similar trends are observed in Figs. 7b and 8b corresponding to the results obtained with an intake air temperature of $120^{\circ} \mathrm{C}$. At the lower intake tem- 
perature (Fig. 8a), the local heat flux peak seems to be highly sensitive to $\mathrm{O}_{2}$ concentration for low injection pressures. This sensitivity is reduced for injection pressures higher than 1000 bar and a change of tendency is also observed around 1500 bar. For higher injection pressures the initial trend is recovered.

The effects on engine performance of high EGR rate and low inlet temperature are expected to be negative. On one hand, the ignition delay is highly sensitive to EGR rate variations. On the other hand, the higher inlet temperature may reduce the ignition delay, which could lead to an increase of in-cylinder pressure peak. In Fig. 9a the sensitivity of the indicated efficiency to both injection pressure and oxygen concentration for tests at the lowest intake temperature $\left(50{ }^{\circ} \mathrm{C}\right)$ is shown. The results show that the indicated efficiency increases almost linearly as the injection pressure increases, and decreases with $\mathrm{O}_{2}$ concentration. However, in the case of higher intake temperature $\left(120^{\circ} \mathrm{C}\right)$, Fig. 9b, the effect of the EGR rate is less noticeable (almost negligible). Finally, as expected, the indicated efficiency is higher when the intake temperature is also higher.

\section{Conclusions}

In this paper, a procedure for measuring the instantaneous heat flux through the walls of the combustion chamber of IC engines was evaluated. With this purpose, a fast response thermocouple was used for measuring the instantaneous fire wall local temperature. Assuming that this temperature signal is periodic, the instantaneous heat flux from the gas was calculated considering that the chamber wall is a semi-infinite body, the heat flux through 
the wall is one-dimensional and at the initial condition the wall temperature is constant and uniform.

The suitability of the procedure for the estimation of heat flux through the walls of the combustion chamber of reciprocating IC engines was checked through motoring and firing tests in a single cylinder research engine. The sensitivity of the proposed procedure to changes in heat transfer was evaluated through tests varying parameters that strongly affect the combustion process. These parameters were the intake air temperature, the injection pressure and the EGR rate for controlling the oxygen concentration at the intake.

The results showed that local heat flux and in-cylinder pressure are highly sensitive to combustion variations, and that the effect on these variables of variations in any of the three parameters mentioned above is quite similar. In addition, the instantaneous heat flux through the walls, and hence the local wall temperatures, are strongly affected by the ignition delay and therefore by the SOC.

Regarding engine performance, expectable results have been obtained. The indicated efficiency is highly sensitive to those parameters affecting the ignition delay. This efficiency strongly depends on the injection pressure and it is less dependent on intake temperature and EGR rate. Furthermore, the results have shown that the effect of the EGR rate on the indicated efficiency is masked when the intake temperature increases.

The experimental procedure used in this paper may become a suitable tool for the development, through parametric studies, of more precise theoretical models for predicting the dissipation of heat through the combustion chamber 
walls of reciprocating IC engines. As a consequence, reliable calculation algorithms for both wall temperatures and heat fluxes could be incorporated into software frequently used for combustion diagnosis in these engines.

\section{References}

[1] Borman G, Nishiwaki K. Internal combustion engine heat transfer. Prog. Energy Combust. Sci. 1987;13(1):1-46.

[2] Lee KS, Assanis DN. Measurements and Predictions of Steady-State and Transient Stress Distributions in a Diesel Engine Cylinder Head. SAE Paper 1999-01-0973. Warrendale, PA: Society of Automotive Engineers Inc.; 1999.

[3] Baker DM, Assanis DN. A methodology for coupled thermodynamic and heat transfer analysis of a Diesel engine. Appl. Math. Model. 1994;18(11):590-601.

[4] Puzinauskas PV, Hutcherson G, Willson BD. Ignition and boost effects on large-bore engine in-cylinder heat transfer. Appl. Therm. Eng. $2003 ; 23(1): 1-16$.

[5] Pang HH, Brace CJ. Review of engine cooling technologies for modern engines. Proc. Inst. Mech. Eng. Part D-J. Automob. Eng. 2004;218(11):1209-1215.

[6] Payri F, Broatch A, Serrano JR, Rodríguez LF, Esmorís A. Study of the potential of intake air heating in automotive DI Diesel engines. SAE 
Paper 2006-01-1233. Warrendale, PA: Society of Automotive Engineers Inc.; 2006.

[7] Broatch A, Luján JM, Serrano JR, Pla B. A procedure to reduce pollutant gases from Diesel combustion during European MVEG-A cycle by using electrical intake air-heaters. Fuel 2008;87(12):2760-2778.

[8] Morel T, Wahiduzzaman S, Fort EF, Tree DR, DeWitt DP, Kreider KG. Heat transfer in a cooled and an insulated Diesel engine. SAE Paper 890572. Warrendale, PA: Society of Automotive Engineers Inc.; 1989.

[9] Cortona E, Onder CH, Guzzella L. Engine thermomanagement with electrical components for fuel consumption reduction. Int. J. Eng. Res. $2002 ; 3(3): 157-170$.

[10] Torregrosa AJ, Broatch A, Olmeda P, Romero C. Assessment of the influence of different cooling system configurations on engine warm-up, emissions and fuel consumption. Int. J. Automot. Technol. 2008;9(4):447-458.

[11] Torregrosa AJ, Olmeda P, Martín J, Degraeuwe B. Experiments on the influence of inlet charge and coolant temperature on performance and emissions of a DI Diesel engine. Exp. Therm. Fluid Sci. 2006;30(7):633641.

[12] Bohac SV, Baker DM, Assanis DN. A global model for steady state and transient S.I. engine heat transfer studies. SAE Paper 960073. Warrendale, PA: Society of Automotive Engineers Inc.; 1996. 
[13] Torregrosa AJ, Olmeda P, Degraeuwe B, Reyes M. A concise wall temperature model for DI Diesel engines. Appl. Therm. Eng. 2006;26(1112):1320-1327.

[14] Torregrosa AJ, Broatch A, Olmeda P, Martín J. A contribution to film coefficient estimation in piston cooling galleries. Exp. Therm. Fluid Sci. 2010;34(2):142-151.

[15] Liu Y, Reitz RD. Multidimensional modelling of engine combustion chamber surface temperatures. SAE Paper 971593. Warrendale, PA: Society of Automotive Engineers Inc.; 1997.

[16] Payri F, Margot X, Gil A, Martín J. Computational study of heat transfer to the walls of a DI Diesel engine. SAE Paper 2005-01-0210. Warrendale, PA: Society of Automotive Engineers Inc.; 2005.

[17] Woschni G. A universally applicable equation for the instantaneous heat transfer coefficient in the internal combustion engine. SAE Paper 670931. Warrendale, PA: Society of Automotive Engineers Inc.; 1967.

[18] Annand WJD, Ma TH. Instantaneous heat transfer rates to the cylinder head surface of a small compression-ignition engine. Proc. Inst. Mech. Eng. 1970-71;185:976-987.

[19] Finol CA, Robinson K. Thermal modelling of modern engines: a review of empirical correlations to estimate the in-cylinder heat transfer coefficient. Proc. Inst. Mech. Eng. Part D-J. Automob. Eng. 2006;220(12):1765-1781. 
[20] Meingast U, Reichelt L, Renz U. Measuring transient wall heat flux under diesel engine conditions. Int. J. Eng. Res. 2004;5(5):443-452.

[21] Rakopoulos CD, Mavropoulos GC. Experimental evaluation of local instantaneous heat transfer characteristics in the combustion chamber of air cooled direct injection diesel engine. Energy 2008;33(7):1084-1099.

[22] Chang J, Filipi Z, Assanis DN, Kuo T, Najt P, Rask R. Characterizing the thermal sensitivity of a gasoline homogeneous charge compression ignition engine with measurements of instantaneous wall temperature and heat flux. Int. J. Eng. Res. 2005;6(4):289-309.

[23] Suzuki Y, Shimano K, Enomoto Y, Emi M, Yamada Y. Direct heat loss to combustion chamber walls in a direct-injection diesel engine: evaluation of direct heat loss to piston and cylinder head. Int. J. Eng. Res. 2005;6(2):119-135.

[24] Bermúdez V, García-Oliver JM, Juliá JE, Martínez S. Engine with Optically Accessible Cylinder Head: a Research Tool for Injection and Combustion Processes. SAE Paper 2003-01-1110. Warrendale, PA: Society of Automotive Engineers Inc.; 2003.

[25] Overbye VD, Bennethum JE, Uyehara OA, Myers PS. Unsteady heat transfer in engines. SAE Transactions 1961;69:461-494.

[26] Chang J, Gürlap O, Filipi Z, Assanis D, Kuo T, Najt P, Rask R. New heat transfer correlation for an HCCI engine derived from measurements of instantaneous heat flux. SAE Paper 2004-01-2996 Warrendale, PA: Society of Automotive Engineers Inc.; 2004. 
[27] Stone R. Introduction to internal combustion engines, third edition, MacMillan Press LTD, 1999.

[28] Annand WJD. Heat transfer in the cylinder of reciprocating internal combustion engines. Proc. Inst. Mech. Eng. 1963;177:973-990.

[29] Payri F, Molina S, Martín J, Armas O. Influence of measurement errors and estimated parameters on combustion diagnosis. Appl. Therm. Eng. 2006;26(2-3):226-236.

[30] Hountalas DT, Mavropoulos GC, Binder KB. Effect of exhaust gas recirculation (EGR) temperature for various EGR rates on heavy duty DI diesel engine performance and emissions. Energy 2008;33:272-283.

[31] Armas O, Rodriguez J, Payri F, Martín J, Agudelo JR. Effect of the trapped mass and its composition on the heat transfer in the compression cycle of a reciprocating engine. Appl. Therm. Eng. 2005;25(17-18):28422853.

[32] Maiboom A, Tauzia X, Hetet JF. Experimental study of various effects of exhaust gas recirculation (EGR) on combustion and emissions of an automotive direct injection diesel engine. Energy 2008;33:22-34. 


\section{Figure captions}

Fig. 1 Schematic diagram and main components of the experimental setup. 1. Piezoelectric pressure sensor, 2. Instantaneous pressure piezorresistive sensor, 3. Mean pressure piezorresistive sensor, 4. Temperature sensor, 5. Valve, 6. Drain valve, 7. Exhaust backpressure valve, 8. Air filter, 9. Compressor, 10. Air cooler, 11. Dryer, 12. Air conditioner, 13. Intake settling chamber, 14. Exhaust settling chamber.

Fig. 2 Cross-sectional view of the instrumented cylinder head.

Fig. 3 Quality of the low-pass filter used in signal processing: a) motored, b) firing.

Fig. 4 Effect of the injection pressure on a) instantaneous temperature, b) temperature swing, c) local heat flux, d) in-cylinder pressure, e) RoHR and f) global heat flux in tests with intake at $120^{\circ} \mathrm{C}$ and $21 \%$ of $\mathrm{O}_{2}$ concentration. Dashed lines correspond to motored tests.

Fig. 5 Effect of the intake air temperature on a) instantaneous temperature, b) temperature swing, c) local heat flux, d) in-cylinder pressure, e) RoHR and f) global heat flux in tests with $21 \%$ of $\mathrm{O}_{2}$ concentration at intake and 1800 bar of injection pressure. Dashed lines correspond to motored tests.

Fig. 6 Effect of $\mathrm{O}_{2}$ concentration at the intake on a) instantaneous temperature, b) temperature swing, c) local heat flux, d) in-cylinder pressure, e) RoHR and f) global heat flux in tests with intake at $120^{\circ} \mathrm{C}$ and 1800 bar of injection pressure. Dashed lines correspond to motored tests. 
564 Fig. 7 Sensitivity of in-cylinder pressure peak to injection pressure and $\mathrm{O}_{2}$ 565 concentration at intake temperature of a) $50{ }^{\circ} \mathrm{C}$, b) $120{ }^{\circ} \mathrm{C}$.

566 Fig. 8 Sensitivity of local heat flux peak to injection pressure and $\mathrm{O}_{2}$ con567 centration at intake temperature of a) $50{ }^{\circ} \mathrm{C}$, b) $120{ }^{\circ} \mathrm{C}$.

568 Fig. 9 Sensitivity of indicated efficiency to injection pressure and $\mathrm{O}_{2}$ concen569 tration at intake temperature of a) $50{ }^{\circ} \mathrm{C}$, b) $120^{\circ} \mathrm{C}$. 
Table 1: Engine main characteristics.

\begin{tabular}{lcc}
\hline Engine type & & Single cylinder, 2 stroke, DI Diesel \\
Bore & {$[\mathrm{mm}]$} & 150 \\
Stroke & {$[\mathrm{mm}]$} & 170 \\
Number of inlet ports & & 4 \\
Number of exhaust ports & & 3 \\
Inlet ports dimensions & {$[\mathrm{mm}]$} & $38 \times 31$ \\
Exhaust ports dimensions & {$[\mathrm{mm}]$} & $58 \times 32$ \\
Dead volume & {$\left[\mathrm{cm}^{3}\right]$} & 118.5 \\
Scavenging & & Curtis loop \\
Injection system & & Common rail \\
\hline
\end{tabular}




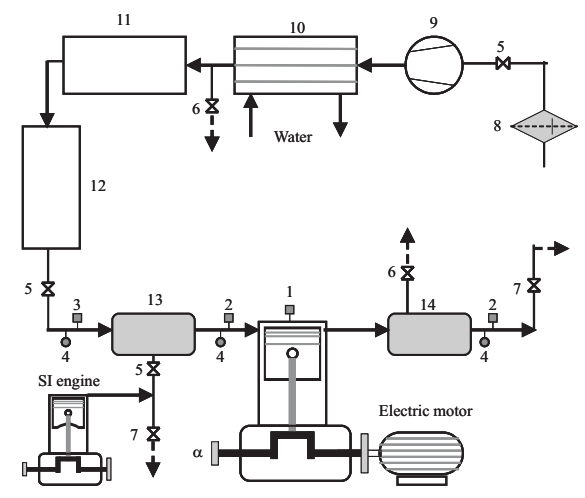

Figure 1: Schematic diagram and main components of the experimental setup. 1. Piezoelectric pressure sensor, 2. Instantaneous pressure piezorresistive sensor, 3. Mean pressure piezorresistive sensor, 4. Temperature sensor, 5. Valve, 6. Drain valve, 7. Exhaust backpressure valve, 8. Air filter, 9. Compressor, 10. Air cooler, 11. Dryer, 12. Air conditioner, 13. Intake settling chamber, 14. Exhaust settling chamber. 


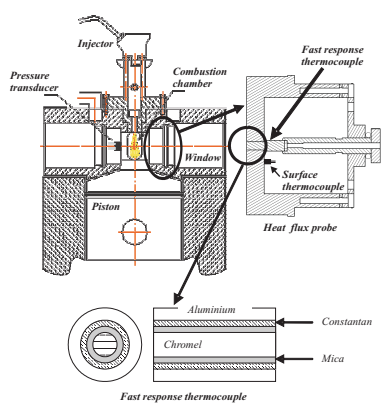

Figure 2: Cross-sectional view of the instrumented cylinder head. 


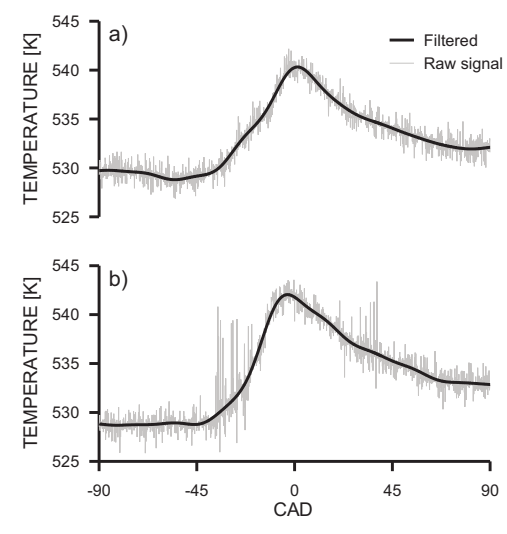

Figure 3: Quality of the low-pass filter used in signal processing: a) motored, b) firing. 

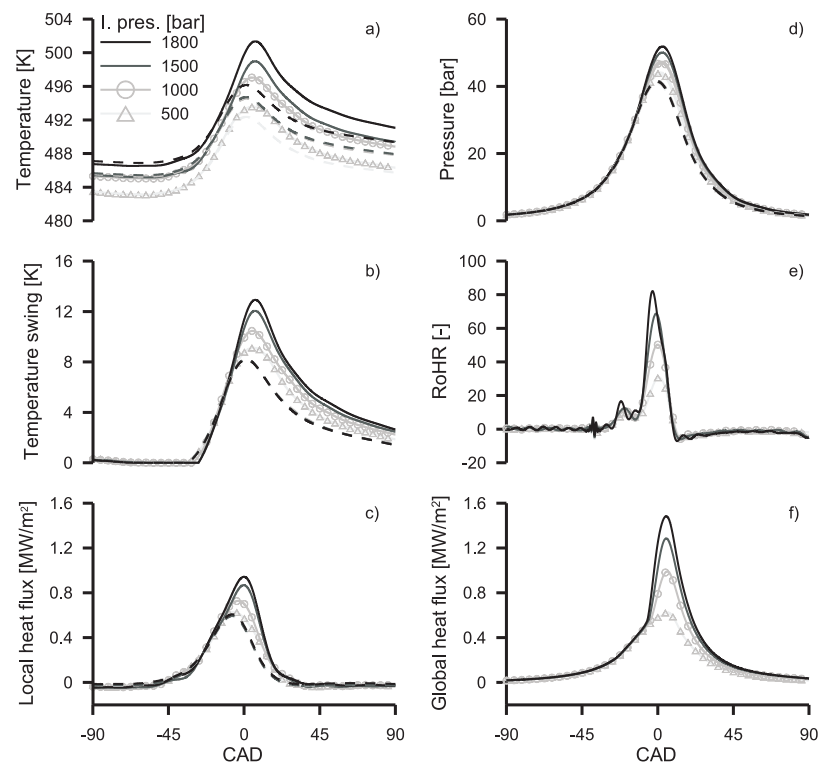

Figure 4: Effect of the injection pressure on a) instantaneous temperature, b) temperature swing, c) local heat flux, d) in-cylinder pressure, e) RoHR and f) global heat flux in tests with intake at $120{ }^{\circ} \mathrm{C}$ and $21 \%$ of $\mathrm{O}_{2}$ concentration. Dashed lines correspond to motored tests. 

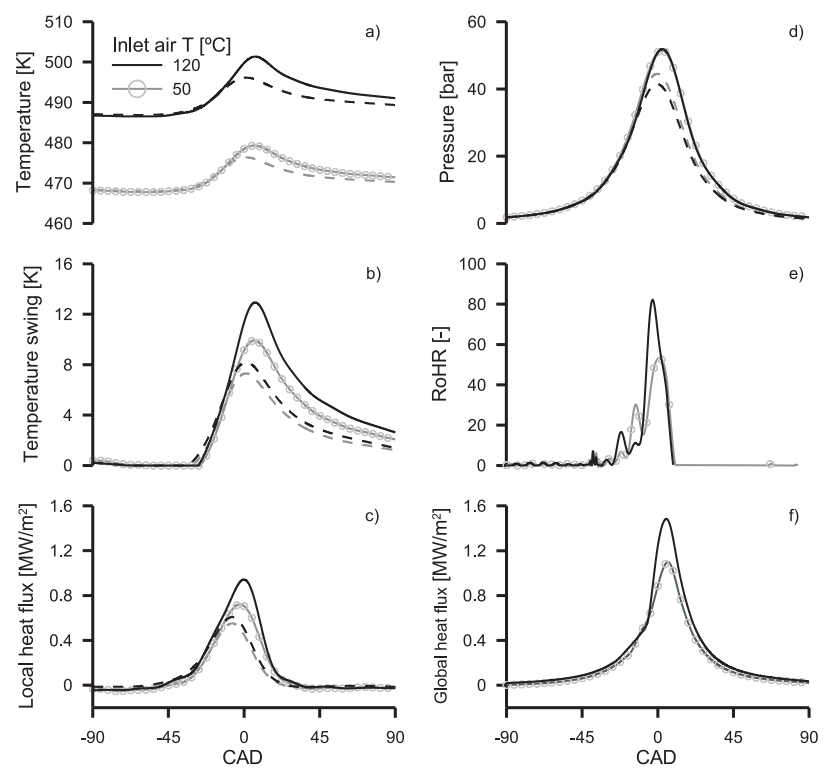

Figure 5: Effect of the intake air temperature on a) instantaneous temperature, b) temperature swing, c) local heat flux, d) in-cylinder pressure, e) RoHR and f) global heat flux in tests with $21 \%$ of $\mathrm{O}_{2}$ concentration at intake and 1800 bar of injection pressure. Dashed lines correspond to motored tests. 

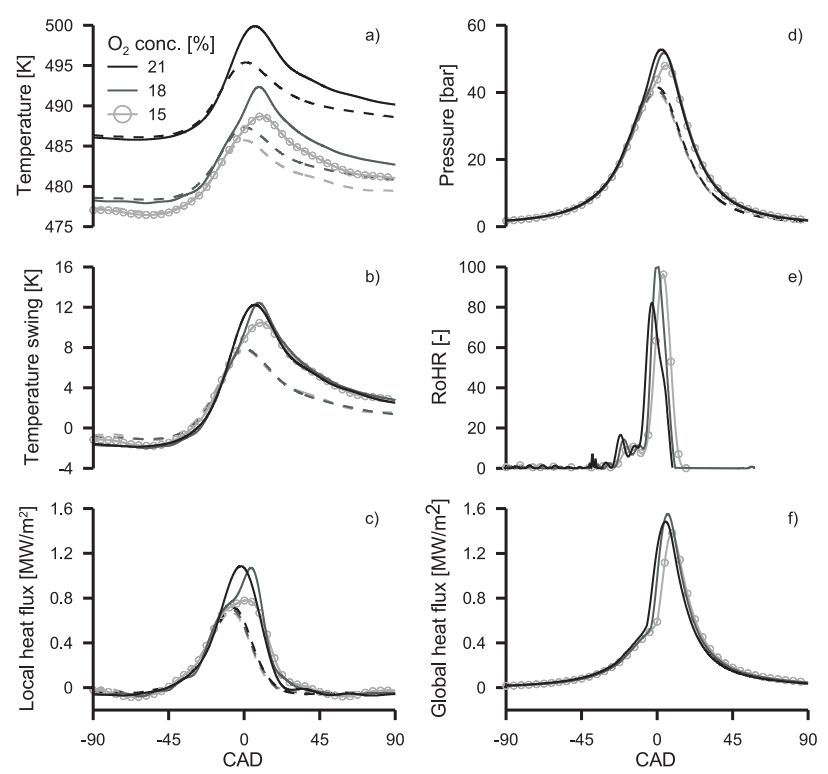

Figure 6: Effect of $\mathrm{O}_{2}$ concentration at the intake on a) instantaneous temperature, b) temperature swing, c) local heat flux, d) in-cylinder pressure, e) RoHR and f) global heat flux in tests with intake at $120^{\circ} \mathrm{C}$ and 1800 bar of injection pressure. Dashed lines correspond to motored tests. 

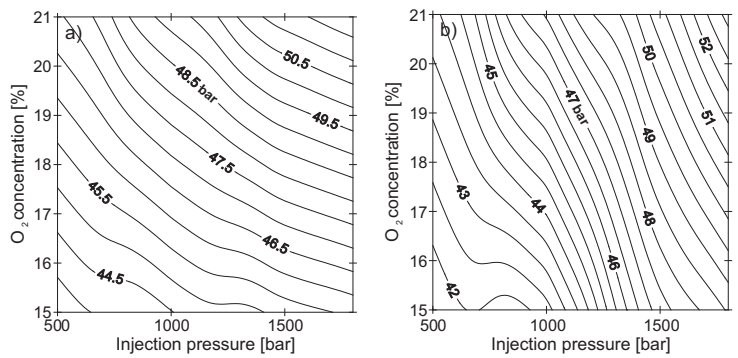

Figure 7: Sensitivity of in-cylinder pressure peak to injection pressure and $\mathrm{O}_{2}$ concentration at intake temperature of a) $50{ }^{\circ} \mathrm{C}$, b) $120^{\circ} \mathrm{C}$. 

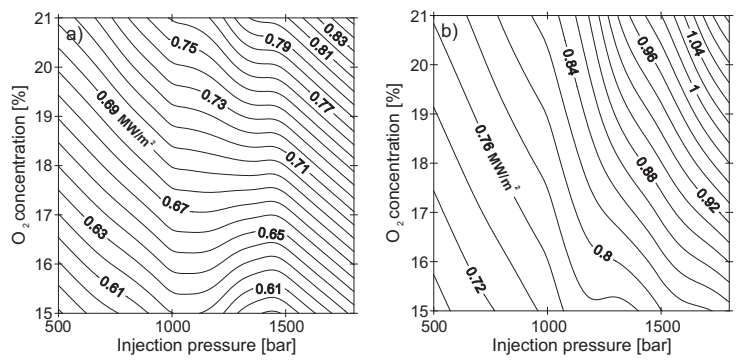

Figure 8: Sensitivity of local heat flux peak to injection pressure and $\mathrm{O}_{2}$ concentration at intake temperature of a) $50{ }^{\circ} \mathrm{C}$, b) $120{ }^{\circ} \mathrm{C}$. 

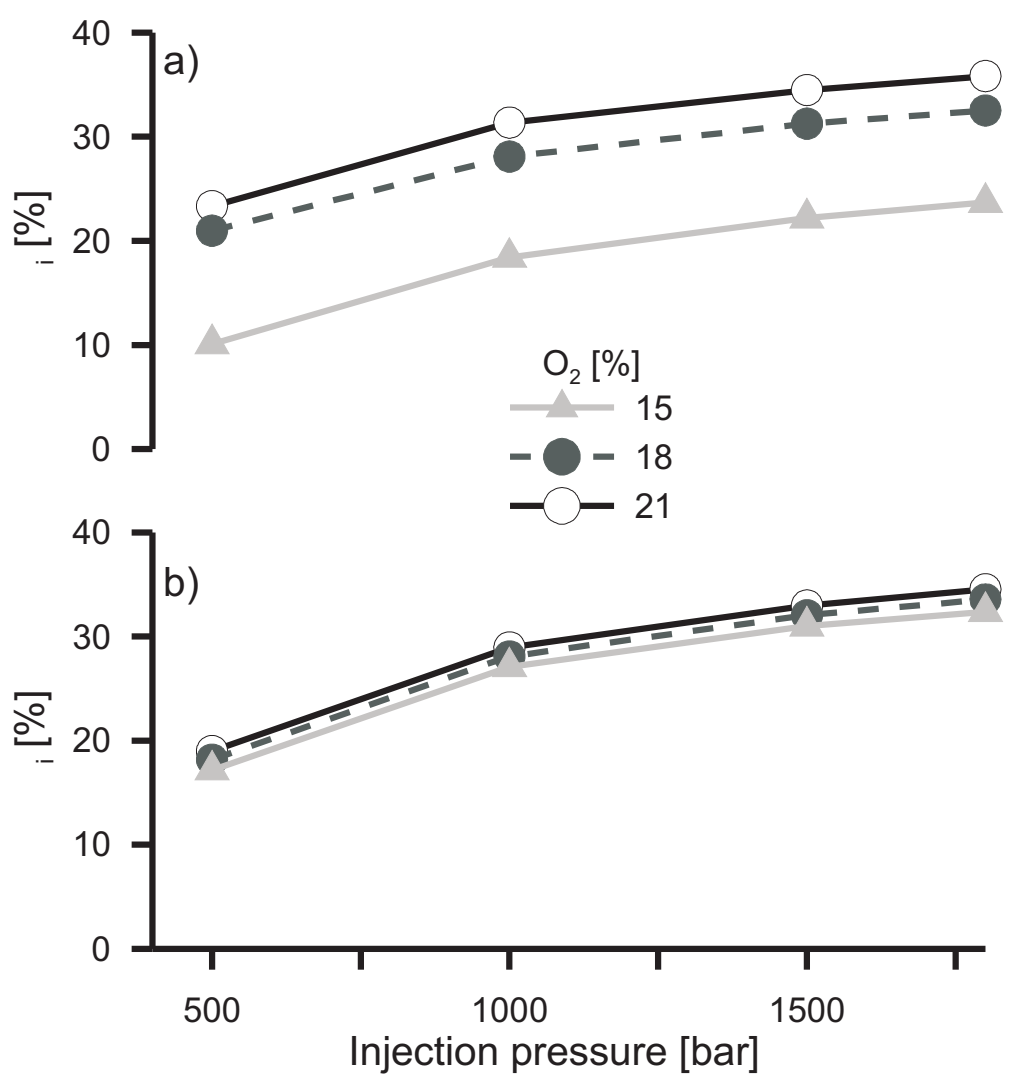

Figure 9: Sensitivity of indicated efficiency to injection pressure and $\mathrm{O}_{2}$ concentration at intake temperature of a) $50{ }^{\circ} \mathrm{C}$, b) $120{ }^{\circ} \mathrm{C}$. 
Table 2: Accuracy of the instrumentation used in this work expressed in $\%$ of full scale.

\begin{tabular}{llc}
\hline Sensor & Variable & Accuracy [\% f.s.] \\
\hline Piezoelectric & In-cylinder pressure & 0.7 \\
Piezoresistive & Intake, exhaust pressure & 0.65 \\
Exhaust gas analyser & $\mathrm{O}_{2}$ concentration & 1.5 \\
Fast response thermocouple & Instantaneous temperature & 0.35 \\
Standard thermocouple & Intake, exhaust, back-side flux & \\
& probe temperatures & 0.3 \\
Encoder & Crankangle & 0.006 \\
Volt and ampere meters & Injection rate & 0.5 \\
\hline
\end{tabular}

